\title{
Fluids and Circuits: A Combined Course
}

\author{
Catherine Skokan, Marcelo G. Simoes, J.P Delplanque, Joan Gosink
}

Colorado School of Mines

\begin{abstract}
In response to a call from the National Science Foundation for curriculum reform and elimination of legacy materials in engineering curricula, faculty at the Colorado School of Mines (CSM) developed and offered a combined set of course modules in Fluids and Circuits. These modules consisted of a two-credit interdisciplinary course in fundamentals, followed by two one-credit modules focusing on applications in fluids, and in circuits, respectively. The course set reduced the overall number of credits from six (three in each of the standard Fluids and Circuits classes) to four through the $2+1+1$ format. The fundamentals course was based on conservation/accounting principles for the concepts of mass, momentum, energy, and charge. Applications courses developed these ideas in the respective disciplines. This paper discusses the combined Fluids and Circuits course, emphasizing the unifying themes and the reduction in course content, and includes an assessment of student comprehension and learning.
\end{abstract}

\section{Introduction}

The demand for reform of engineering education is insistent and undeniable. Shaping the Future $^{1}$ the Final Report of the Review of Undergraduate Education in Science, Mathematics, Engineering, and Technology, highlights the need for departments to take a leading role in the development of curriculum "that engages and motivates the broadest spectrum of students....", and in the development of "meaningful connections with employers to provide appropriately responsive educational experiences for prospective ... members of the work force", and urges departments to "foster interdisciplinary education". Nevertheless, there is complacency and a lack of enthusiasm for major curriculum and pedagogical reform. Among the factors discouraging reform are the traditions of each discipline regarding legacy materials, a lack of knowledge of emerging areas, and externally or internally imposed credit limitations.

The Division of Engineering at the Colorado School of Mines (CSM) offers a design-oriented, interdisciplinary, accredited non-traditional undergraduate program in engineering with specialization in a branch of civil, electrical, environmental, or mechanical engineering. In the Division, we have a tradition of innovation with respect to interdisciplinary curriculum, a young and dynamic faculty (currently five NSF Career awardees), and relative freedom from 
State control on credit allocations. This provides us with a particularly strong position to undertake major curricular and pedagogical reform.

In support of reform activities, the National Science Foundation (NSF) initiated a new program, Department-Level Reform of Undergraduate Engineering Education in 2002. This program called for innovative strategies to effect reform, including streamlining the curriculum through the reduction of legacy materials, introducing topics in emerging areas of engineering, and forming integrated partnerships that cross disciplines and focus on technological systems. CSM engineering faculty interested in curriculum reform developed a proposal to this solicitation; the proposal was funded in fall 2002. This paper describes a specific objective of the project, namely the unification of two traditional core courses required of all engineering students, Fluids and Circuits, into a combined pilot set of courses through a "two plus one" approach. The unification resulted in the reduction of the total number of required credit hours from six (three in each of the traditional courses) to four ( $2+$ $1+1$ ). The paper presents the conceptual unifying philosophy, as well as specific examples of topics included and excluded.

\section{Background}

During the last two decades there have been numerous projects funded by NSF and other agencies to address problems in engineering education. The NSF Engineering Education Coalitions have been leaders in these efforts ${ }^{2}$. Even the new requirements for accreditation through the Accreditation Board for Engineering and Technology, Inc. (ABET ${ }^{7}$ ) stress the value of innovation and individual development of engineering objectives. There is particular concern related to the expansion of curriculum, specifically, the perceived need to include more and more topics into an already overloaded schedule. If new topics are to be introduced, it is clear that some topics will have to be eliminated. At both a state and school level, there has also been a push to reduce the total number of credits required for graduation. Strategies for eliminating topics gives rise to this project.

\section{Models for streamlining the curriculum}

We investigated several models for streamlining the curriculum to compare their pedagogical value and proven success in improving student learning. Selection of an appropriate model was guided by our understanding of model compatibility with the CSM curriculum and student profile. We were also concerned with the potential of the models to serve as transitional courses for advanced topics in emerging areas.

Two models for streamlining the curriculum are briefly described here:

\section{1) Combining standard courses}


Several universities have combined standard courses such as Statics with another course, such as Strength of Materials or Dynamics or Circuits ${ }^{12,13,14}$. For example, the Geophysics Department at CSM offers a course in Linear Systems that combines many concepts from statics, mechanics, and circuits. However, applications to relevant engineering topics are few. California Institute of Technology offers a challenging undergraduate course that combines Statistical Thermodynamics and Heat Transfer. A textbook combining thermodynamics, fluid flow, and heat transfer was recently published ${ }^{16}$. Texas A\&M offers three courses based on Conservation Principles - in Engineering Mechanics, Thermal Sciences, and Continuum Mechanics. The first combines concepts from statics and dynamics, and the second, concepts from thermodynamics and fluid flows. Textbooks with these themes have been developed based on conservation (or "budget equation") principles ${ }^{12,13,14,15}$.

This approach is straightforward; two courses are combined, but most materials are presented in the standard format. Specific materials must be eliminated, and time available for coverage of topics is reduced. However, it is difficult to see how this model can be integrated with the goal of including new materials in emerging areas.

\section{2) Fundamentals courses}

Dartmouth College offers three courses that combine concepts from basic engineering science: Systems, Distributed Systems and Fields, and Discrete and Probabilistic Systems ${ }^{17}$. Each course is integrative in the sense that examples and applications are introduced from mechanics, fluids, circuits, information theory, and other basic engineering topics. Typically, each course unites these topics in terms of the similarity of mathematical structures. This approach encourages students to understand the underlying and unifying fundamental principles, and the application of principles to specific phenomena. Similarly, Drexel University offers a course in Systems, focused around a text in differential equations ${ }^{18}$, with applications in classical mechanics, mixing problems, demographics, carbon dating, chemical and nuclear reactions, and elementary electrical circuits.

\section{Selected Strategy}

After reviewing these and other models, we decided upon a strategy based primarily on a combination of models 1 (combining standard courses) and 2 (fundamentals courses). We applied these models to the development of course modules that would compress traditional Fluids and Circuits courses. Following model 1, we used the conservation/accounting approach developed in the Foundations Coalition ${ }^{12,14,15}$ for concepts from Fluids and from Circuits. We chose Fluids and Circuits as the pilot course because the individual courses contain similar mathematical structures; this is consistent with model 2 as developed at Dartmouth $^{8}$. Specifically, both of these courses are primarily made up of "lumped parameter" topics, as opposed to distributed topics and to statistical topics. We classify lumped parameter problems as those with uniform properties, seldom requiring integration. 
Distributed parameter topics have non-uniform properties and utilize differential equations liberally. Strength of Materials and Heat Transfer are good examples of distributed parameter topics. Statistical parameter topics may be Advanced Thermodynamics and Statistical Systems. Thus our combined Fluids and Circuits course will focus on topics with uniform properties. As an example, we have omitted development of the Navier Stokes Equation, a topic that is included in the standard Fluids course, and also omitted tedious algebraic calculations for resistive networks, usually taught in standard Electric Circuits courses from the combined course.

Our original plan involved the development of several mandatory two-credit fundamentals courses, covering lumped parameters, distributed parameters, and statistical parameters, followed by an array of one-credit applications courses. Applications courses would build on the unifying themes presented in the fundamentals courses and would include introduction to emerging engineering topics. Thus, for example, we would offer one-credit fluids applications courses in biofluidics, computational fluid dynamics, and small-scale pumps and turbines. (The latter course would be appropriate for our new minor program in Humanitarian Engineering - see paper 2004-1781). In this way we could reduce the total number of credit hours by at least six credits, while offering new courses in emerging areas. The revised curriculum would be more flexible to new topics, since the application courses could be changed as the need arises.

For this pilot study, we chose to offer a single fundamentals course, followed by two applications courses that would provide greater in-depth coverage of the requisite course materials. In this way, the students in the pilot sections would not be penalized in terms of their ability to pass the FE exam or other standard measures. Special permission was given to the students enrolled in the pilot classes by the CSM administration to permit a reduction in the total number of credit hours.

\section{Course Logistics}

Our goal was to reduce the traditional credit count by at least two credits, from the standard six credits (three each for Fluids and for Circuits). This was accomplished through a $2+1+1$ format. The first course - the fundamentals course - entitled Fluids and Circuits, counted for two credits, and was followed by two one-credit "applications" courses in Fluids and Circuits, respectively. Due to the timing of the grant, the fundamentals course was offered during field session 2003. The fundamentals course was thus scheduled for two and one-half hours a day, three days a week for three weeks during summer 2003. At CSM all students are required to complete a field session of at least three credits in their respective disciplines. Thus, CSM students are comfortable with an intensive three-week summer program, commencing immediately after the end of the Spring semester. However, although we advertised the combined Fluids and Circuits aggressively, only six students registered. Nevertheless, as will 
be discussed, the group provided a diverse population in terms of performance and background, and we believe that reasonable conclusions can be reached about students' grasp of the materials and reactions to the approach.

In the fall 2003 semester, the same group of students registered for the two one-credit applications courses in Fluids and Circuits, respectively. With this small number of students, student and faculty agreement determined timing for the applications courses. Students and faculty agreed to meet for three hours once a week for five weeks in both of the applications modules, in sequence. This compressed time schedule resulted in some difficulties, as will be discussed in the section on Assessment.

\section{The Fundamentals course: Fluids and Circuits}

The goal of the course was to give students an introduction to engineering problems through an understanding of mathematical and conservation principles. These basic principles were applied to electrical circuits and fluids problems. Specific learning objectives were:

1. Students will apply mathematical techniques to engineering (electrical and fluids) problems. These techniques include matrix algebra, linearity, and transient response.

2. Students will apply conservation principles to engineering problems (power, mass, charge, momentum, energy)

3. Students will solve example fluid and electrical problems using dimensional analysis, modeling techniques, etc

Our first problem was to find a common text for lumped parameter topics in Fluids and Circuits. We chose the text by Glover et al. ${ }^{12}$ since it presents a cogent explanation of conservation/accounting principles. As an example, the conservation/accounting principle method makes use of a straightforward form of the Reynolds Transport Equation:

For the general property $\mathrm{B}$

$\Delta \mathrm{B} /\left.\Delta \mathrm{t}\right|_{\text {sys }}=$ flux of B into the $\mathrm{CV}-$ flux of B out of the CV $+\Delta \mathrm{B} /\left.\Delta \mathrm{t}\right|_{\text {gen }}-\Delta \mathrm{B} /\left.\Delta \mathrm{t}\right|_{\text {cons }}$

Where

$\mathrm{B}$ is an intensive property (see below), and $\mathrm{CV}$ is the control volume for the analysis. $\Delta B /\left.\Delta t\right|_{\text {sys }}$ is the rate of change of $B$ in the control volume.

$\Delta B /\left.\Delta t\right|_{\text {gen }}$ is the rate of generation of $B$ within the control volume (source of $B$ ). $\Delta \mathrm{B} /\left.\Delta \mathrm{t}\right|_{\text {cons }}$ is the rate of consumption of $\mathrm{B}$ within the control volume (sink for $\mathrm{B}$ ).

If we look at a given time step, this becomes:

$\left.\mathrm{B}\right|_{\text {sys, end }}-\left.\mathrm{B}\right|_{\text {sys, beg }}=\left.\mathrm{B}\right|_{\text {in }}-\left.\mathrm{B}\right|_{\text {out }}+\left.\mathrm{B}\right|_{\text {gen }}-\left.\mathrm{B}\right|_{\text {cons }}$

We then applied this general equation to all problems and topics in the entire course.

Equations 1 and 2 can be applied to mass, momentum, energy, and charge. Table 1 provides a summary of sinks and sources considered in the combined course. We found that repetition 
of the conservation principle for each property was well accepted by the students, and easily assimilated (see the assessment section, below).

\begin{tabular}{|l|l|l|}
\hline B & Sources & Sinks \\
\hline $\mathrm{m}=$ mass & NA & NA \\
\hline $\mathrm{mv}=$ momentum & $\begin{array}{l}\mathrm{F}_{\mathrm{g}}=\text { force of gravity } \\
\mathrm{F}_{\mathrm{P}}=\text { force of pressure }\end{array}$ & $\begin{array}{l}\mathrm{F}_{\mathrm{g}}=\text { force of gravity } \\
\mathrm{F}_{\mathrm{P}}=\text { force of pressure } \\
\mathrm{F}_{\mathrm{f}}=\text { force of friction }\end{array}$ \\
\hline $\mathrm{E}=$ energy & Pump & $\begin{array}{l}\text { Turbine } \\
\text { Friction } \\
\text { Resistors, capacitors, } \\
\text { inductors }\end{array}$ \\
\hline $\mathrm{Q}=$ Charge & $\begin{array}{l}\text { Battery, power } \\
\text { supply }\end{array}$ & NA \\
\hline & NA & \\
\hline
\end{tabular}

\section{Table 1. Sources and Sinks for intensive properties}

Another theme unifying the Fluids and Circuits sections was the distinction between intensive and extensive properties. We provided students explicit guidance on the differences between intensive and extensive properties, and this is summarized in Table 2.

\begin{tabular}{|l|l|l|}
\hline & Intensive properties & Extensive properties \\
\hline & Independent of sample size & $\begin{array}{l}\text { Can be counted or experimentally } \\
\text { measured }\end{array}$ \\
\hline Dependent on sample size \\
\hline Fluids & $\mathrm{T}, \mathrm{P}, \rho, \mathrm{v}, \mathrm{u}, \mathrm{ke}, \mathrm{pe}, \mathrm{s}$ & $\mathrm{m}, \mathrm{V}, \mathrm{U}, \mathrm{KE}, \mathrm{PE}, \mathrm{S}, \mathrm{mv}$ \\
\hline Circuits & $\rho, \mathrm{j}, \mathrm{E}, \mathrm{\sigma}, \mathrm{q} / \mathrm{m}^{3}$ & $\mathrm{~V}, \mathrm{R}, \mathrm{S}, \mathrm{I}, \mathrm{q}, \mathrm{L}, \mathrm{C}, \mathrm{W}$ \\
\hline
\end{tabular}

Where

\begin{tabular}{|l|l|}
\hline Fluids & Circuits \\
\hline $\mathrm{T}=$ temperature & $\rho=$ resistance \\
\hline $\mathrm{P}=$ pressure & $\mathrm{J}=$ current density \\
\hline$\rho=$ density & $\mathrm{E}=$ electric field \\
\hline $\mathrm{v}=$ velocity & $\sigma=$ conductivity \\
\hline $\mathrm{u}=$ internal energy & $\mathrm{q} / \mathrm{m}^{3}=$ charge density \\
\hline $\mathrm{ke}=$ specific kinetic energy & $\mathrm{V}=$ voltage \\
\hline $\mathrm{pe}=$ specific potential energy & $\mathrm{R}=$ resistance \\
\hline $\mathrm{s}=$ specific entropy & $\mathrm{I}=$ current \\
\hline $\mathrm{m}=$ mass & $\mathrm{q}=$ charge \\
\hline $\mathrm{V}=$ volume & $\mathrm{L}=$ inductance \\
\hline $\mathrm{U}=$ internal energy & $\mathrm{C}=$ capacitance \\
\hline $\mathrm{KE}=$ kinetic energy & $\mathrm{W}=$ work \\
\hline
\end{tabular}




\begin{tabular}{|l|l|}
\hline $\mathrm{PE}=$ potential energy & \\
\hline $\mathrm{S}=$ entropy & \\
\hline
\end{tabular}

Table 2. Summation of intensive and extensive properties.

Noting that there is duplication in the usage of symbols (e.g., $\rho$ is density and resistance), we explained to the students that this type of duplication is common in engineering, and the correct interpretation must be inferred by the usage and content. This introduced the topic of dimensions. Although the Buckingham Pi Theorem was postponed until the follow-on onecredit course, the importance of dimensional homogeneity was stressed throughout the fundamentals course. Indeed, dimensional homogeneity became an essential component of this course, and we found that the students readily switched from Fluids to Circuits notations, and back again. We note that the Buckingham Pi Theorem is clearly a lumped parameter topic; however, with the limited time available in the fundamentals course, it was impossible to cover this topic within the course and thus was postponed to the fluids applications course.

During the class, time was divided between lecture and blackboard work by the students. Students worked both formally during class-time and informally outside of class on problem solving. The students were assessed against the objectives through observation of blackboard work, homework problem solutions, a mid-term exam and a final exam. The resulting grades were typical of the standard fluids and electrical classes.

\section{Content and Removed Materials from the Fundamentals Course}

The Fundamentals course was taught by two authors of this paper (JG and CS) with experience teaching Fluids and Circuits, respectively, but with limited knowledge of the other course materials. Both faculty attended all classes and learned the new materials with the students, asking questions when uncertain of new concepts. This reinforced an informal atmosphere that encouraged student participation and confidence. With the compressed format and timing, our challenge was to present fundamental materials from both the traditional Fluids and Circuits courses in the available twenty-seven contact hours. We also wanted to employ a pedagogy of active learning with students solving problems at the blackboard. This section summarizes the topics covered and those omitted.

\section{1) Fluids topics}

The topics of mass, momentum, and "Bernoulli Energy" were presented in terms of the conservation/accounting principle. Repetition of the conservation/accounting principle provided a systematic way of explaining concepts, and arguably, made the topics easier to understand (see section on Assessment)

Using the terminology presented in Glover et al. ${ }^{12}$, mass is a conserved property (no sinks or sources), while momentum and energy are accounted properties (non-zero sinks and sources). 
Although the fundamentals course focused primarily on lumped parameters, we were able to introduce a few simple examples of distributed parameters through the mass conservation problems. Specifically, in some cases, students had to calculate mass flux with a non-uniform velocity profile. These examples were later shown to relate to the differences between friction factors in laminar and turbulent flow, as applied to the energy equation.

We provided students with notes for the energy equation rather than using the presentation in Glover et al. ${ }^{12}$ for several reasons. First, instead of using the classical sign convention from mechanical engineering, that text uses the traditional sign convention from chemical engineering, which adapts rather awkwardly to the source/sink notation in equation (1). We found that our explanation, -- pumps are sources of energy, while turbines and friction are sinks for energy, -- was more easily understood by the students. In addition, we used the Haaland equation ${ }^{38}$ for the friction factor rather than the equation used in the Glover text. Accuracy is about the same, and the Haaland, although non-linear, is not transcendental.

Hydrostatic problems were introduced, and these did require derivation of a differential equation (distributed parameters) to explain the pressure gradient term. We used the jumpacross method $^{38}$, which is always a student favorite, to analyze multiple fluid manometers. Therefore, the students easily accepted this topic. Students also participated in a hands-on demonstration to measure a linear pressure distribution in a tall beaker.

Topics omitted from the fundamentals course, which are included in our standard Fluids course, include the development of the Navier Stokes and the continuity equations with examples, an introduction to open channel flow, pipe networks and non-circular pipes, minor losses, the Buckingham Pi Theorem, external flows, drag and lift, and an introduction to pumps.

The breadth of the standard Fluids course at CSM reflects its usage by many disciplines (civil, electrical, environmental, mechanical, petroleum, and metallurgical engineering students). The new combined course would reduce credits hours for all these disciplines, while providing opportunities for students to enroll in specialized discipline-specific courses. For example, electrical engineering students could omit further applications courses related to fluids entirely. The fundamentals course should provide them with essential knowledge for the Fundamental of Engineering (FE) exam. Civil and environmental engineering students may elect to take the applications course in open channel flow and ground-water flow, while mechanical engineering students might elect to take applications courses in computation fluid mechanics or biofluidics. The commonality of a fundamentals course is efficient, and the applications courses provide a flexible and versatile method for achieving disciplinary depth and exploration. 


\section{2) Circuits topics}

The topics of charge and energy were presented in terms of the conservation/accounting principle. Examples of conservation of charge were illustrated with the operation of a battery and a capacitor. With the addition of Ohm's Law, the details of Kirchhoff's Current Law were presented using conservation principles. The concept of voltage was developed in terms of conservation of energy and power. Circuit analysis through Kirchhoff's Current and voltage Laws were then emphasized. The concepts of Thevenin and Norton Equivalency and superposition were presented as further examples. The topic of maximum power transfer was included. Finally, first order RL and RC circuit analysis with switching was covered. Topics omitted from the fundamental course that our usually included in our standard introductory circuits course were phasor analysis, AC power, diodes, transistors, and operational amplifiers. These topics were successfully incorporated in the electrical " +1 " module during the fall semester.

\section{Description of Electrical Circuits Module}

The Electrical Circuits follow-on module was taught in five sessions that met weekly for three hours. Principles and Applications of Electrical Engineering ${ }^{39}$ was adopted as the course textbook. The rationale for this class was to teach the principles of circuits and keep in-depth system perspective, supporting the integration with the other follow-on module on Fluids. The following topics were taught:

- AC Network Analysis

- Frequency Response and System Concepts

- AC Power

- Operational Amplifiers

- Semiconductors and Diodes

- Bipolar Junction Transistors, Operation, Circuit Models and Applications

There were some cooperative and project-oriented activities. For example, short-seminars on research-based topics were presented in the second week. Pairs of students wrote one-page reports and gave ten-minute presentations about topics such as Ultracapacitors and Superconducting Magnetic Energy Storage systems. A mid-term exam was given in the third week. The mid-term was cross-evaluated among peers. Students exchanged exams and applied rubrics to evaluate their colleagues' performance. The following topics were assessed:

- Did the student have exactly the expected answer?

- Did the student have the right reasoning?

- Did the documentation of the problem helped to evaluate the answer?

- Was it clear overall? 
Each form was returned to the instructor who evaluated the peer review. Then individual interviews were conducted by the instructor to assess each student's progress.

In the last week a laboratory activity was conducted. A single-phase resistive-inductivecapacitive circuit was analyzed on paper with phasor diagrams and evaluated in the laboratory using an oscilloscope. A take-home final test was conducted, with comprehensive problems. At the end of the five-week period the instructor individually met with the students to discuss the problems of the final exam and assess their overall learning perspective.

\section{Fluids Application Module}

The fluid application module follows a format similar to the Electrical Circuits Module. The class met for three hours once a week for five weeks. The book used was "Fluid Mechanics," by F. M. White ${ }^{38}$. The topics to be covered were selected to maximize continuity with the Fundamentals course while avoiding redundancy and introducing major fluid flow applications. Hence, the first lecture focused on Dimensional Analysis (including $\Pi$ Theorem and Models and Prototypes) because of the inherent multidisciplinarity of the topic. It was followed by a lecture in which the definition of a fluid was discussed and which centered on fundamental flow quantities such as the velocity field and the stress field, as well as the concept of viscosity. Applications covered both internal flow (pipe flow systems) and external flow (Fluid drag and immersed bodies). Another goal was to try and combine some topics to promote delivery and learning efficiency. For example, while there was no lecture dedicated specifically to pumps and turbines, pumps were used as examples in the lectures on dimensional analysis as well as pipe flow system analysis so that the topics of pump performance and pump/system matching were covered. Note that this type of approach has also been used in the traditional Fluids course.

\begin{tabular}{|l|ll|}
\hline \multicolumn{1}{|c|}{ TOPICS INCLUDED } & \multicolumn{1}{c|}{ TOPICS EXCLUDED } \\
\hline - $\begin{array}{l}\text { Dimensional Analysis, П -Theorem, } \\
\text { Models and Prototypes }\end{array}$ & $\bullet \begin{array}{l}\text { Introduction to differential analysis of } \\
\text { fluid flow }\end{array}$ \\
- $\begin{array}{l}\text { What is a fluid? Velocity field, Stress } \\
\text { field, Viscosity. }\end{array}$ & $\bullet \quad \begin{array}{l}\text { Flow in non-circular ducts. } \\
\text { Pipe Flow (including minor losses, } \\
\text { multiple path flow systems, and flow } \\
\text { meters). }\end{array}$ & $\bullet$ Open Channel Flow \\
Fluid Drag of Immersed Bodies. & $\bullet \quad$ Pumps \\
\hline
\end{tabular}

The excluded topics were either topics that would be part of a different, optional module in a permanent implementation (e.g. Introduction to differential analysis of fluid flow or Open channel flows) or topics that the students were prepared to acquired on their own if needed (e.g. flow in non-circular ducts), based on the material that was covered explicitly. 
The small size of the group allowed the implementation of active learning techniques such as in-class, student-driven problem solving, but these still remained relatively limited. Testing and assessment included weekly 10-15 minute quizzes. These quizzes were directly based on one of nine problems from the text that had been assigned as practice problems the previous week. In order to provide the students with maximum control and flexibility in terms of the distribution of their workload, on-demand access to the solutions of these practice problems was provided using a password-protected web site. Finally, a take-home exam was assigned at the end of the module. This was an individual assignment that required the use of computational tools (spreadsheet or symbolic calculator). The students had four days to complete the assignment and were allowed to interact only with the instructor for questions regarding that assignment.

\section{Assessment}

Assessment consisted of standard course evaluations, faculty observations, informal student comments, and a student focus group. Firstly, we noted that the grade distribution for the courses was typical for the standard Fluids and Circuits courses. During the fundamentals course, we found that students collaborated extensively, forming a regular study group to work homework problems. This perhaps could be expected from a small group of (six) students learning new materials in a compressed time frame. Nevertheless, this was a somewhat diverse group (three foreign students and three American students), and their interactions were extremely positive.

The issues raised in the student focus group, and some of the student responses are provided here:

Compare your experience with that of your colleagues.

- Some friends are now having a hard time in Circuits.

- See others struggling with concepts in thermo.

- Forgot Fluids and Circuits materials over the summer.

- Got lots of help in Fluids and Circuits; made topics easier.

- Liked common concepts approach.

- Feels he can do everything except transistors.

List topics that were new to you that you now understand.

- Examples from fluids/ wind tunnel.

- Practical applications.

What are some connections between fluids and circuits?

- Sum of the currents/sum of the mass flux.

- Same math (except non-linear turbulent friction).

- Same logic.

- Conservation principle. 
Would you have chosen the same route with what you know now?

- Yes.

What would you change about the time and length of classes?

- The three-hour block in the fall was too much, especially the time of day (4:30-7:30 PM). (NB: This was probably the biggest complaint of the students.)

- Both fundamentals and applications courses should be offered in the summer.

What would you change about implementation?

- Bring in Multidisciplinary Engineering Laboratory (a required course) applications and connections.

- Try other combinations.

- Add a project to the fundamentals course.

- Polish the lesson plan (timing) to even out assignments.

Comment on collaborative vs. individual learning.

- With small class we knew everyone.

- Worked well together.

Finally, on a positive note, one student volunteered that the course helped him develop the skills needed to address problems systematically when he had no prior experience.

\section{Recommendations and Conclusions}

Implementation of this reform, course compression, into a permanent feature of the curriculum is challenging. There are at least three major obstacles to achieving full implementation: faculty buy-in and preparation, administrative support, and appropriate textbooks.

\section{Faculty buy-in and preparation}

Deciding which classes will be combined and how the overall curriculum will be affected require intensive faculty discussion and agreement. The fundamentals courses are really quite different from standard courses, requiring collaboration among faculty in several disciplines, and appreciation for overarching principles. Faculty may require training in new disciplines before adopting the $2+1$ structure. There is a great difficulty in simultaneously presenting multiple levels of abstraction, and faculty must present a cogent integration of theoretical principles in the introductory course, linked to a depth of knowledge in follow-on modules.

Administrative support

Proceedings of the 2004 American Society for Engineering Education Annual Conference \& Exposition Copyright (C) 2004, American Society for Engineering 
Another challenge is related to financial support for reform, since this program can attract more students and encourage faculty with its novel approach and reduction in inherited legacy materials. Therefore, commitment from the institution is important, first to support gradual implementation and continuous growth of the program, second to allow reform in the school timetable and scheduling of classes that depend on the $2+1$ sequence.

The $2+1$ structure may offer an incentive to faculty in terms of scheduling possibilities. If the applications (one-credit) courses are taught in blocks of five week, teaching assignments could be adjusted so that a faculty member teaches only ten or even five weeks out of the fifteen week semester.

\section{Appropriate textbooks}

Legacy elimination for teaching new materials requires a new approach to textbook design. Rather than the usual comprehensive texts that provide a top-down explanation of disciplinary principles, texts used in the introductory courses should present linked fundamental themes, such as conservation, accounting, property characteristics, and common constitutive laws. These texts should be concise and somewhat repetitive in repeating the fundamental themes. The texts needed in the Applications courses will contain a minimum of theoretical background, focusing on how the fundamental themes are demonstrated in specific cases. Again, these texts should be concise, allowing the individual instructor to add relevant and current examples. Thus, some support such as the NSF/EMD program would be important in designing the right textbook for the class.

\section{Acknowledgement}

Financial support from the National Science Foundation through the grant NSF-EEC-0230699 is gratefully acknowledged.

\section{References}

1. Shaping the Future, New Expectations for Undergraduate Education in Science, Mathematics, Engineering, and Technology, A Report on its Review of Undergraduate Education, Advisory Committee to the National Science Foundation, Directorate for Education and Human Resources, NSF 96-139, 1996, 76 pp.

2. http://www.eng.nsf.gov/eec/coalitions.htm

3. http://www.ehr.nsf.gov/ehr/DUE/

4. http://www.nsf.gov/home/crssprgm/igert/start.htm

5. http://www.nsf.gov/pubs/2001/nsf01121/nsf01121.htm

6. http://www.ed.gov/legislation/FedRegister/announcements/2002-2/041102a.html

7. http://www.abet.org/criteria.html

8. http://thayer.dartmouth.edu/thayer/academicsadmissions/undergrad-courseslong.html

9. http://egweb.mines.edu/eggn250/

10. http://egweb.mines.edu/eggn350/ 
11. http://egweb.mines.edu/eggn450/

12. C.J. Glover, K. M. Lunsford, and J. A. Fleming, Conservation Principles and the Structure of Engineering, 5th Edition, McGraw-Hill College Custom Series, 1995.

13. Thomas C. Pollock, Properties of Matter, 5th Edition, McGraw-Hill College Custom Series, 1995.

14. Louis J. Everett, Understanding Engineering Systems Via Conservation, 2nd Edition, McGraw-Hill College Custom Series, 1992.

15. C. J. Glover and Harry L. Jones, Conservation Principles for Continuous Media, McGraw-Hill College Custom Series, 1992.

16. T. A. Çengel and R. H. Turner, "Fundamentals of Thermal-Fluid Science," McGrawHill, 2001

17. http://thayer.dartmouth.edu/thayer/academicsadmissions/undergrad-courses.html

18. William Boyce and Richard Diprima, Elementary Differential Equations, $7^{\text {th }}$ Edition, New York: John Wiley 2001

19. James H. McClellan, Ronald W. Schafer, and Mark A. Yoder, Experiences in Teaching DSP First in the ECE Curriculum, Frontiers in Education Conference, 1997. 27th Annual Conference. Teaching and Learning in an Era of Change. Proceedings, Volume: 2 , 1997 Page(s): 891 -895 vol.2

20. Jordan Rosenthal and James H. McCllelan, Animations and GUIs for Introductory Engineering Courses, Proceedings of the International Conference on Engineering Education, Session 6E4, pp. 6E4-11-16, August 6-10, 2001, Oslo, Norway.

21. http://egweb.mines.edu/aceps/

22. http://egweb.mines.edu/ibdms/

23. http://web.mit.edu/ocw/

24. http://weblab.mit.edu/

25. Task Committee on the Academic Prerequisites for Professional Practice, Policy Statement 465: Why We Must Raise the Bar, Civil Engineering, Civil Engineering, Vol. 72, No. 4, pp. 60-65 and 94-95, April 2002.

26. ASEE Joint Task Force on Engineering Education Assessment, "Assessment White Paper - A Framework for the Assessment of Engineering Education", (1996).

27. https://www.fastlane.nsf.gov/servlet/showaward?award=0127806

28. B. M. Olds and R.L. Miller, “An Assessment Matrix for Evaluating Engineering Programs”, Engineering Ed., 87, No. 2, 173-178, (1998).

29. B. M. Olds and R. L. Miller, "A Measure of Success: Here's How to Design and Evaluation Plan for Your Next Educational Research Project", ASEE Prism, December 1997, pp. 24-29.

30. Commission on Behavioral and Social Sciences and Education, John D. Bransford, Ann L. Brown, and Rodney R. Cocking, editors, "How People Learn: Brain, Mind, Experience, and School: Expanded Edition (2000)", National Academy Press, Washington, D.C.

31. http://www.fastlane.nsf.gov/servlet/showaward?award $=0085849$

32. http://www.fastlane.nsf.gov/servlet/showaward?award=0121691

33. https://www.fastlane.nsf.gov/servlet/showaward?award=0127806

34. Robert Magnan editor, 147 Practical Tips for Teaching Professors, Atwood Publishing, Madison, Wisconsin, 1990.

Proceedings of the 2004 American Society for Engineering Education Annual Conference \& Exposition Copyright $\left({ }^{\circ} 2004\right.$, American Society for Engineering 
35. Richard Pregent, Charting Your Course: How to Prepare to Teach More Effectively, Magna Publications, Inc., 1994.

36. Edward Ernst and Irene Peden, Realizing the New Paradigm Engineering Education, Proceedings, Engineering Foundation Conferences, NY, NY, 1998.

37. Barbara Gross Davis, Tools for Teaching, Jossey-Bass Publishers, San Francisco, CA, 1998.

38. F. M. White, Fluid Mechanics, $5^{\text {th }}$ Edition, McGrawHill, 2003.

39. Giorgio Rizzoni, Principles and Applications of Electrical Engineering, McGraw-Hill, 2000.

\section{Biographies}

\section{CATHERINE SKOKAN}

Catherine K. Skokan (cskokan@mines.edu) received her Ph. D. in Geophysical Engineering from the Colorado School of Mines. She is presently an Associate Professor of Electrical Engineering at Colorado School of Mines. Her research interests include engineering applications of geophysics, curriculum development, and k-12 outreach.

\section{JOAN GOSINK}

Dr. Joan Gosink is a Professor Emerita and Former Director of the Engineering Division at CSM. Dr. Gosink twice served as a Program Director at NSF. Among her other strengths, Dr. Gosink is an experienced ABET evaluator.

\section{JEAN-PIERRE DELPLANQUE}

Dr. Jean-Pierre Delplanque is an Associate Professor in the Engineering Division at CSM. His research interests focus on theoretical and computational fluid dynamics and transport phenomena in inert and reactive multiphase flow with applications in combustion and materials processing. He has an Engineering Diploma from ENSEEIHT (Toulouse, France), an M.S. ("DEA") in Mechanics from the National Polytechnic Institute of Toulouse (France), and an M.S. and Ph.D. in Mechanical and Aerospace Engineering from UC Irvine.

\section{MARCELO G. SIMOES}

Dr. Marcelo Simoes is an Associate Professor of Engineering and a recent recipient of an NSF Career award. He received his B.S. and M.Sc. degrees in electrical engineering from the University of Sao Paulo, his Ph.D. in electrical engineering from the University of Tennessee, and his D.Sc. in mechanical engineering from the University of Sao Paulo. His research interests relate to the design, analysis, simulation and modeling of a hightorque low-speed multi-phase permanent magnet brushless machine for electric vehicle applications. Other research interests relate to fuzzy logic based photovoltaic peak power tracking, solar powered vehicles, neural network modeling and renewable energy systems. 